\title{
KILAT
}

Vol. 9, No. 1, April 2020, P-ISSN 2089-1245, E-ISSN 2655-4925

DOI: https://doi.org/10.33322/kilat.v9i1.784

\section{Studi Analisis Dampak Overload Transformator Terhadap Kualitas Daya Di PT. PLN (Persero) UP3 Pondok Gede}

\author{
Samsurizal $^{1}$; Benyamin Hadinoto ${ }^{2}$ \\ ${ }^{1,2}$ Teknik Elektro, Institut Teknologi PLN \\ ${ }^{1}$ samsurizal@itpln.ac.id
}

\begin{abstract}
The population of the population in big cities, special areas of the big cottage growth continues to increase according to the BPS in 2015 amounted to 2,733,240 and increased in 2019 3,013,851. With an increasing population, it will increase electricity demand in the region. The JS 190 Distribution Station provided a significant increase in transformer loading which achieved a $95.75 \%$ loading presentation of a $200 \mathrm{kVA}$ transformer capacity. Therefore it is necessary to improve by looking at these conditions, one of which is by doing an uprating transformer or adding a power transformer with a larger capacity to $400 \mathrm{kVA}$. From the results of the increase obtained loading results decreased to $52.75 \%$ which means the reversal transformer is one method that can be used to overcome the overload.
\end{abstract}

Keywords: Overload, Uprating, Power Quality, Transformator, electricity demand

\begin{abstract}
ABSTRAK
Pertumbuhan penduduk dikota besar, khususnya wilayah pondok gede pertumbuhan nya terus meningkat menurut BPS tercatat pada tahun 2015 sebesar2.733.240 dan meningkat di tahun 2019 3.013.851. Dengan meningkatnya jumlah penduduk tentunya berdampak pula peningkatan akan kebutuhan listrik di wilayah tersebut. Pada Gardu Distribusi JS 190 terdapat kenaikan yag signifikan pada pembebanan transformator yang mencapai presentasi pembeban $95.75 \%$ dari kapasitas ttansformator 200 kVA. Oleh karenanya perlu dilakukan perbaikan dengan melihat kondisi tersebut salah satunya dengan melakukan uprating transformator atau menambah daya transformator dengan kapasitas yang lebih besar menjadi 400 kVA. Dari hasil uprating diperoleh hasil pembebanan menurun menjadi $52.75 \%$ yang berarti uprating transformator merupakan salah satu metode yang bisa digunakan untuk mengatasi overload.
\end{abstract}

Kata kunci: Pembebaban Lebih, Uprating, Kualitas Daya, Trafo,Kebutuhan Listrik 


\section{PENDAHULUAN}

Dengan seiring laju pertumbuhan penduduk setiap tahunnya yang semakin pesat. Kebutuhan listrik pun ikut mengalami peningkatan yang signifikan. Dengan semakin banyaknya penduduk dan kebutuhan energi listrik yang dibutuhkan, maka semakin besar juga pasokan listrik yang disalurkan ke pelanggan. Maka pembebanan pada transformator juga semakin bertambah, bahkan hingga melebihi presentase pembebanan yang sudah ditentukan dan akan mempengaruhi kualitas daya yang dihasilkan.

Pasokan listrik yang ada di Indonesia sekarang ini masih menggunakan jasa layanan PT PLN (Persero) untuk mendistribusikannya. Khususnya Bekasi, Pondok Gede merupakan kota yang besar dan penduduk setiap tahunya bertambah, pada tahun 2015 total penduduk di Bekasi 2.733.240 jiwa, di tahun 2016 2.803.283, sedangkan tahun 2017 2.873.484, tahun 2018 penduduknya sebanyak 2.943.859 dan di tahun 2019 bahkan sudah mencapai 3.013.851 jiwa menurut Badan Pusat Statistik. Sedangkan kebutuhan pelanggan listrik ditahun 2015 tercatat 324.175, ditahun 2016 tercatat 330.084, ditahun 2017 tercatat 334.688, ditahun 2018350.733 dan ditahun 2019 pada bulan juli sudah mencapai 359.098 ribu pelanggan listrik. Maka dari itu, kebutuhan pelanggan PT PLN (Persero) tersebut semakin bertambah, dengan semakin bertambahnya pelanggan maka beban yang dipinggul oleh transformator semakin besar pula yang di tanggung sehingga akan mempengaruhi kualitas dari pasokan daya listrik. Khususnya pada Gardu JS 190 dengan tipe gardu susun di Area Pondok Gede,beban yang ditanggung oleh transformator semakin lama semakin bertambah dengan seiringnya bertambahnya penduduk dan kebutuhan listrik, sehingga beban yang di pikul juga semakin bertambah mencapai $95,75 \%$ dan daya yang sudah terpakai sudah mencapai 191,84 dari 200 kVA. Lantas dengan pembebanan 95,75\% sudah melampaui batas standard PLN yaitu kurang dari $80 \%$.

Dalam penelitiannya sebelumnya [1] menjelaskan mengenai uprating transformator untuk meningkatkan operasi pendistribusian tenaga listrik kepada konsumen dengan simulasi Electrical Transient Analyzer Program (ETAP). Metode uprating merupakan peningkatan kapasitas daya transformator 30MVA menjadi 60 MVA pada sistem $150 \mathrm{kv} / 20 \mathrm{kv}$. Pada penelitian lain [2] menyatakan bahwa umur transformator harus dipelihara agar dapat bertahan sesuai umur yang seharusnya. Umur transformator dapat berkurang akibat pengaruh pembebanan, pembebanan yang tinggi menyebabkan kerusakan pada isolasinya.

\section{METODE/PERANCANGAN PENELITIAN}

\subsection{Perancangan Penelitian}

Dalam penelitian ini dilakukan perancangan adapun diagram alir ditunjukkan pada Gambar 1. Dibawah ini 


\section{KILAT}

Vol. 9, No. 1, April 2020, P-ISSN 2089-1245, E-ISSN 2655-4925

DOI: https://doi.org/10.33322/kilat.v9i1.784

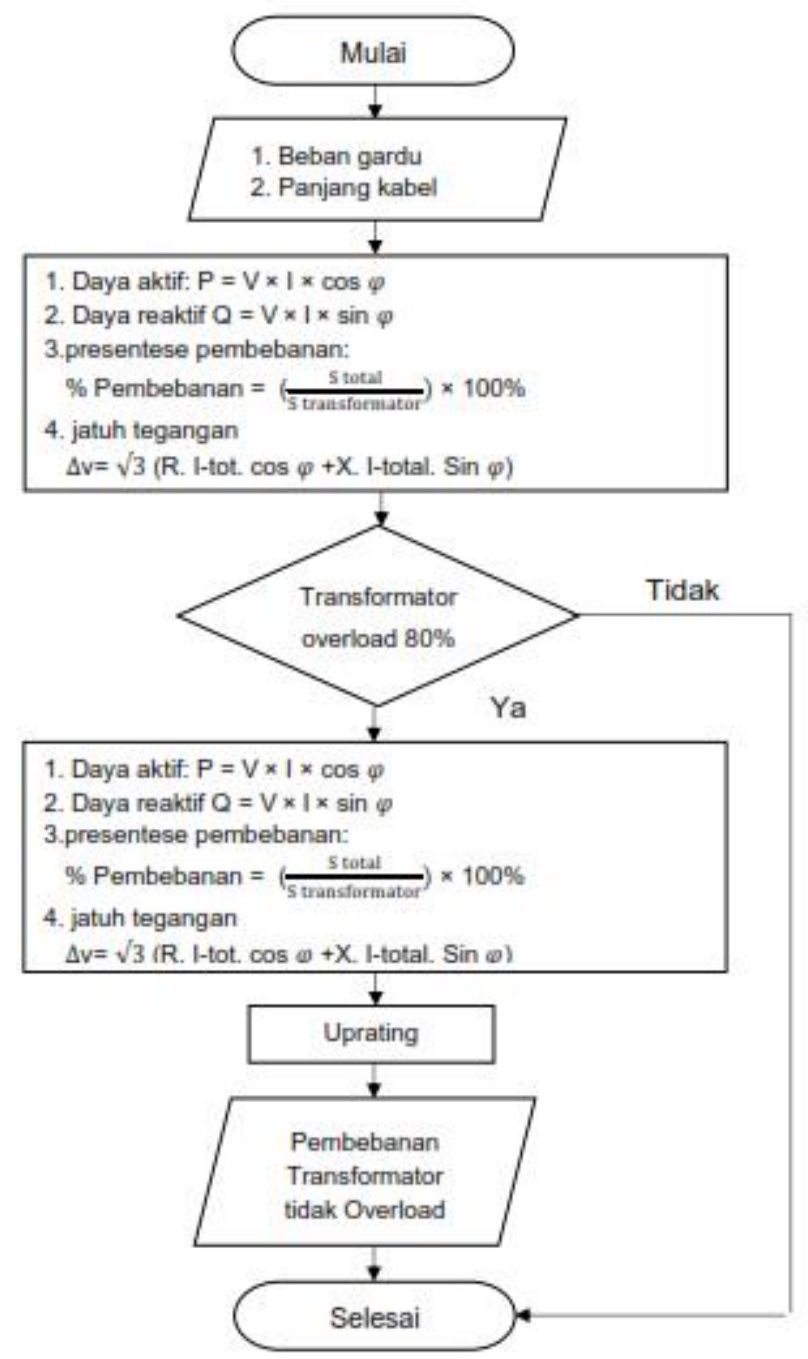

Gambar 1. Diagram alir perancangan penelitian uprating transformator

Untuk memperoleh data-data yang dibutuhkan dalam perhitungan, maka menggunakan data dari hasil pengukuran beban gardu tersebut yang diketahui mengalami overload. Hal ini menyebabkan kualitas tegangan sampai pada pelanggan tidak sesuai kriteria tegangan standar sistem tegangan rendah yang mengacu SPLN seri 1 tahun 1995 [3] [4] yaitu sebagai berikut: Variasi tegangan pelayanan ditetapkan maksimum $+5 \%$ dan minimum $10 \%$ terhadap tegangan nominal [4].

Tabel 1. Ketentuan variasi tegangan pelayanan [4]

\begin{tabular}{|c|c|}
\hline \multicolumn{2}{|c|}{ Ketentuan variasi tegangan pelayanan } \\
\hline $\begin{array}{c}\text { Tegangan nominal } \\
(\mathrm{v})\end{array}$ & Variasi tegangan pelayanan \\
\hline $230 / 400$ & $\begin{array}{r}\text { Minimum }-5 \% \\
\text { maksimum } 10 \%\end{array}$ \\
\hline $400 / 690$ & \\
\hline 1000 & \\
\hline
\end{tabular}

Setelah dilakukan pengukuran beban di Gardu, permasalahan yang terjadi pada Gardu distribusi dengan nomor Gardu JS190 pada penyulang gram, di GI pondok kelapa Area Pondok 
Gede dengan kondisi transformator overload. Transformator didapati dengan mengalami overload dari kapasitas transformator sebesar $200 \mathrm{kVA}$.

Transformator distribusi merupakan komponen yang sangat penting dalam mendistribusikan tenaga listrik ke konsumen. Pemilihan kapasitas kVA transformator distribusi didasarkan beban yang akan di layani. Diusahakan transformator distribusi mendekati 80\% [5]. Transformator distribusi umumnya mencapai efesiensi maksimum (rugi-rugi transformator minimum). Bila beban transformator terlalu besar, maka dilakukan pergantian transformator, atau penyisipan atau mutasi transformator atau penambahan daya (melayani beban kecil dimutasikan kebeban besar). Transformator distribusi dianggap overload apabila beban transformator melebihi $80 \%$ dari kapasitas transformator atau arus nominal (In). Beban transformator agar di sarankan $<80 \%$ untuk semua merk transformator [6] [7].

Dalam menghitung presentase pembebanan suatu transformator dapat diketahui dengan menggunakan persamaan sebagai berikut [8] [9]:

$$
\% \text { Pembebanan }=\left(\frac{\text { s Total }}{\text { STransformator }}\right) \times 100 \%=
$$

Dimana:

$$
\begin{array}{ll}
\text { Stotal } & =\text { Daya total tersalurkan }(\mathrm{kVA}) \\
\mathrm{S} & =\text { Daya transformator }(\mathrm{kVA})
\end{array}
$$

Untuk melakukan pengukuran dapat dihitung dengan menggunakan persamaan ini. Dasar perhitungan besaran pengukuran energi listrik adalah sebagai berikut [10]:

Daya aktif (P)

$$
\mathrm{P}=\mathrm{V} \times \mathrm{I} \times \cos \mathrm{f}
$$

Dimana:

$$
\begin{aligned}
& \text { P: Daya aktif (Watt) } \\
& \text { I : Arus (Ampere) } \\
& \text { V : Tegangan (Volt) }
\end{aligned}
$$

Daya semu (S) [8] [11]

$$
S=\sqrt{P^{2}+Q^{2}}
$$

Dimana:

$$
\begin{aligned}
& \mathrm{S}: \text { Daya semu }(\mathrm{kVA}) \\
& \mathrm{P}: \text { Daya aktif }(\mathrm{kW}) \\
& \mathrm{Q}: \text { Daya reaktif }(\mathrm{kVAr})
\end{aligned}
$$

Daya reaktif (Q) [8]

$\mathrm{Q}=\mathrm{V} \times \mathrm{I} \times \sin \mathrm{f}$

Dimana:

Q : Daya reaktif (kVAr)

$\mathrm{V}$ : Tegangan (Volt)

I : Arus (Ampere) 


\section{KILAT}

Vol. 9, No. 1, April 2020, P-ISSN 2089-1245, E-ISSN 2655-4925

DOI: https://doi.org/10.33322/kilat.v9i1.784

Metode uprating transformator ini juga berfungsi untuk mengatasi overload pada transformator. Metode ini paling simpel atau mudah tanpa syarat-syarat apapun untuk mengatasi transformator overload. Metode uprating yaitu penambahan daya transformator dari 100kVA menjadi 200kVA, $200 \mathrm{kVA}$ di uprating menjadi 400kVA. Adapun beberapa faktor kenapa harus di lakukannya uprating transformator untuk mengurangi overload [12].

1. Finansial

Jika dilihat perbedaan dari transformator sisip. Metode uprating atau penambahan daya transformator adalah jauh lebih murah di banding transformator sisip. Karena pada dasarnya, uprating transformator ini hanya menambah daya misalkan dari 200kVA menjadi $400 \mathrm{kVA}$ sedangkan transformator sisip ini harus melakukan beberapa perenecanaan dari segi perencanaan pembangunan, perhitungan, finansial, lahan, waktu, tempat yang tepat seperti diperkotaan, material, penjualan kVA terhadap konsumen seperti didaerah perkotaan sehingga penjualan listrik kekonsumen tidak sia sia dan lain sebagainya. Disamping itu metode transformator sisip jauh lebih mahal dibanding uprating transformator. Karena metode uprating transformator hanya menambah kapasitas daya yang lebih besar dari sebelumnya.

2. Lahan

Untuk melakukan uprating transformator hanya menambah daya yang lebih besar dari daya sebelumnya. Sehingga tidak membutuhkan lahan yangluas.

3. Material

Metode uprating transformator tidak dibutuhkan lagi untuk memberi material sehingga metode ini adalah yang paling tepat khususnya wilayah Pondok gede.

\section{HASIL DAN PEMBAHASAN}

Diketahui panjang jaringan tegangan rendah dari gardu js 190 ke Ke tiang terakhir yaitu sepanjang $504 \mathrm{~m}$ dari total panjang kabel $3636 \mathrm{~m}$ dengan jumlah tiang saluran tegangan rendah sebanyak 29 tiang Penghantar kabel twisted $3 \times 35+1 \times 50 \mathrm{~mm}^{2}$ pada umumnya di PT PLN UP3 Pondok Gede, menggunakan kabel JTR dengan inti almunium dengan resisntansi phasa 0,867 untuk netral 0,581 dan reaktansi 0,3790 menurut buku PLN 1 "kriteria desain enjinering konstruksi jaringan distribusi tenaga listrik dan SPLN 64 1985" [3].

Gardu induk pondok kelapa, penyulang gram dan dengan nomor gardu JS 190 merupakan gardu distribusi tipe gardu susun. Pada penyulang gram ini dibebani 24 gardu distribusi. Ini adalah gardu dengan nomor JS 190 sebelum dilakukannya uprating transformator dari $200 \mathrm{kVA}$ menjadi $400 \mathrm{kVA}$. Dari hasil perhitungan sebelum dan sesudah uprating transformator, maka didapat hasil seperti ditunjukkan pada tabel 2.

Tabel 2. Perbandingan sebelum dan sesudah uprating transformator

\begin{tabular}{|c|c|c|c|c|c|c|c|c|}
\hline \multirow[b]{2}{*}{ Phasa } & \multicolumn{4}{|c|}{ Sebelum Uprating } & \multicolumn{4}{|c|}{ Sesudah Uprating } \\
\hline & $\begin{array}{c}\text { Voltage } \\
\text { (v) }\end{array}$ & $\begin{array}{c}\text { Arus } \\
\text { (i) }\end{array}$ & $\begin{array}{c}\cos \\
\varphi \\
\end{array}$ & $\begin{array}{c}\% \\
\text { Presentase } \\
\text { beban }\end{array}$ & $\begin{array}{c}\text { Voltage } \\
\text { (v) }\end{array}$ & $\begin{array}{c}\text { Arus } \\
\text { (i) }\end{array}$ & $\begin{array}{c}\text { Cos } \\
\varphi \\
\end{array}$ & $\begin{array}{c}\% \\
\text { Presentase } \\
\text { beban }\end{array}$ \\
\hline $\mathrm{R}$ & 223 & 282 & 0,960 & \multirow{3}{*}{$95,75 \%$} & 228 & 287 & 0,964 & \multirow{3}{*}{$52,75 \%$} \\
\hline $\mathrm{S}$ & 225 & 242 & 0,962 & & 231,4 & 283 & 0,965 & \\
\hline $\mathrm{T}$ & 222 & 335 & 0,972 & & 229,5 & 350 & 0,970 & \\
\hline
\end{tabular}


Setelah mendapatkan beban sebelum dan sesudah uprating transformator, ternyata tegangan kiriman pada trafo sebelum uprating lebih rendah dibandingkan dengan setelah uprating, hal tersebut menjadikan pengaruh terhadap tegangan yang ada diujung jaringannya, maka dari itu dilakukan perhitungan secara manual untuk mengetahui tegangan di ujung.

\section{Jatuh tegangan diujung jaringan sebelum Uprating Transformator}

$$
\begin{aligned}
& \Delta \mathrm{v}=\sqrt{ } 3(\mathrm{R} \times \mathrm{I} \text {-total } \mathrm{x} \cos \varphi+\mathrm{X} \times \mathrm{I} \text {-total } \times \sin \varphi) \\
& \Delta \mathrm{v}=\sqrt{ } 3(436,96 \times 286,3 \times 0,96+191,01 \times 286,3 \times 0,25) \\
& \Delta \mathrm{v}=231,69 \mathrm{~V}
\end{aligned}
$$

\section{Jatuh tegangan diujung jaringan sesudah Uprating Transformator}

$$
\begin{aligned}
& \Delta \mathrm{v}=\sqrt{ } 3(\mathrm{R} \times \mathrm{I} \text {-total } \times \cos \varphi+\mathrm{X} \times \mathrm{I} \text {-total } \times \sin \varphi) \\
& \Delta \mathrm{v}=\sqrt{ } 3(436,96 \times 306,66 \times 0,96+191,01 \times 306,66 \times 0,25) \\
& \Delta \mathrm{v}=248,17 \mathrm{~V}
\end{aligned}
$$

\begin{tabular}{|c|c|c|c|c|c|}
\hline \multicolumn{2}{|c|}{ Penghantar } & \multirow{2}{*}{$\begin{array}{c}\mathrm{KHA} \\
(\mathrm{A})\end{array}$} & \multicolumn{2}{|c|}{$\begin{array}{l}\text { Resistansi Penghantar pada } \\
20^{\circ} \mathrm{C}(\mathrm{ohm} / \mathrm{km}\end{array}$} & \multirow{2}{*}{$\begin{array}{c}\text { Reaktansi } \\
\text { pada } \\
\mathrm{f}=50 \mathrm{~Hz} \\
(\mathrm{ohm} / \mathrm{km})\end{array}$} \\
\hline Jenis & Ukuran & & Fasa & Netral & \\
\hline \multirow{4}{*}{$\begin{array}{l}\text { Kabel } \\
\text { twisted }\end{array}$} & $3 \times 35+1 \times 50 \mathrm{~mm}^{2}$ & 125 & 0,867 & 0,581 & 0,3790 \\
\hline & $3 \times 50+1 \times 50 \mathrm{~mm}^{2}$ & 154 & 0,641 & 0,581 & 0,3678 \\
\hline & $3 \times 70+1 \times 50 \mathrm{~mm}^{2}$ & 196 & 0,443 & 0,581 & 0,3572 \\
\hline & $3 \times 95+1 \times 50 \mathrm{~mm}^{2}$ & 242 & 0,308 & 0,581 & 0,3449 \\
\hline
\end{tabular}

Adapun hasil perhitungan besar jatuh tengan diujung jaringan ditunjukkan pada tabel 3 .

Tabel 3. Nilai Reaktansi dan Resistansi Kabel

Seiring bertambahnya penduduk, tercatat pada tahun 2015 jumlah penduduk dibekasi 2.733.240 dan di 2019 sudah mencapai 3.013.851 jiwa, menurut Badan Pusat Statistik. Dengan bertambahnya penduduk, kebutuhan listrik pun ikut bertambah tercatat di tahun 2015324.175 dan ditahun 2019 sudah mencapai 359.098 dan ini adalah pertumbuhan kebutuhan listrik pun meningkat dengan signifikan. Dengan bertambahnya kebutuhan listrik, ini berdampak pada Gardu JS 190 beban yang dipikul sudah mencapai 95,75\% dari kapasitas yang terpakai $191.84 \mathrm{kVA}$ dan dari total daya transformator sebesar $200 \mathrm{kVA}$.

Transformator mempunyai batasan-batasan dalam operasinya. Dengan presentase pembebanan yang tinggi sebesar 95,75\% dari kapasitas yang dipakai sebesar $191.84 \mathrm{kVA}$ dan dari total kapasitas daya transformator sebesar $200 \mathrm{kVA}$. Apabila transformator digunakan secara terusmenerus dalam kondisi overload, maka akan mengalami peningkatan pada suhu dan panas pada transformator pun bertambah. Sehingga akan merusak isolasi, material dan transformator akan rusak. Selain itu, mempengaruhi kualitas daya transformator, drop tegangan pada ujung jaringan dan berakibat susut umur pada transformator.

\section{KESIMPULAN DAN SARAN}

Dari hasil diatas didapat bahwa perhitungan sebelum uprating transformator, presentase dayanya adalah sebesar $95,75 \%$. Setelah uprating transformator atau penambahan daya 


\section{KILAT}

Vol. 9, No. 1, April 2020, P-ISSN 2089-1245, E-ISSN 2655-4925

DOI: https://doi.org/10.33322/kilat.v9i1.784

transformator dari $200 \mathrm{kVA}$ menjadi $400 \mathrm{kVA}$, pembebenannya telah berkurang menjadi 52,75\%. Dilihat dari data dan dari hasil perhitungan setelah uprating, bahwa metode uprating dapat menjadi salah satu metode yang dapat digunakan mengatasi overload transformator pada gardu Js190.

Dan dengan pertumbuhan penduduk semakin tahun semakin bertambah, maka diperlukan, perencanaan dan menganalisa kedepannya untuk wilayah yang berpontensi pertumbuhan yang semakin pesat.

\section{DAFTAR PUSTAKA}

[1] F. A. Wasahua, "Efek pembebanan terhadap penyusutan umur transformator pada gardu distribusi," STT PLN, Jakara, 2019.

[2] J. Edianto, "Pemasangan Trafo sisip guna memperbaiki tegangan ujung pada penyulang viona di PLN. (Persero) Area Teluk Naga," STT-PLN, Jakarta, 2018.

[3] B. P. 1, Kriteria disain enjineering konstruksi jaringan distribusi tenaga listrik, Jakarta: PT.PLN (Perseero).

[4] S. 1, Tegangan Standar, Jakarta: PT.PLN (Persero), 1995.

[5] I. Sarimun, Buku saku pelayanan teknik (Yantek), Depok: Garmond SPLN, 2014.

[6] SPLN, Petunjuk pemilihan dan penggunaan peleburan pada sistem distribusi tegangan menengah, Jakarta: PLN, 1985.

[7] S. 7, Spesifikasi Transformator Distribusi, Jakarta: PLN, 1997.

[8] S. Daman, Sistem distribusi tenaga listrik, Padang: UNP, 2009.

[9] Soebagio, Transformator Daya, Surabaya: ITS Press, 2012.

[10] T. Berlian, Transmisi Daya Listrik, Yogyakarta: Andi Yogyakarta, 2013.

[11] A. Kadir, Transfomator, Jakarta: Universitas Indonesia, 2010.

[12] M. Rahmat, "Remaining Life Assesment Transformator 150/20kV dengan Metode Degradasi Isolasi," Jakarta, 2017.

[13] S. 77, Transformator Tegangan, Jakarta: PT.PLN (Persero), 1987. 